\title{
PINTURAS CORPORALES EN EL FIN DEL MUNDO. UNA INTRODUCCIÓN AL ARTE VISUAL SELK'NAM Y YAMANA
}

\author{
BODY PAINTINGS FROM THE END OF THE WORLD. AN INTRODUCTION \\ TO THE VISUAL ART OF SELK'NAM AND YAMANA
}

\begin{abstract}
Dánae Fiore*
En este trabajo se realiza una introducción al uso de pinturas corporales por las sociedades Selk'nam y Yamana de Tierra del Fuego. Se presentan las fuentes de datos (textos y fotografías) acerca de estas prácticas y los métodos de trabajo usados en el análisis de su construcción y sus contenidos. Con el objeto de buscar similitudes y diferencias en el uso de pinturas entre ambas sociedades, se incluyen análisis cuantitativos de algunos aspectos de su empleo (sexo, edad, porciones del cuerpo pintadas de los individuos fotografiados), análisis de factores formales de las pinturas (técnicas y diseños) y análisis cualitativos de algunos de los procesos implícitos en el uso de las pinturas. Finalmente, las dinámicas sociales identificadas, en especial, en relación a las divisiones de sexo, se contextualizan vinculándolas con los contenidos de algunos mitos y con los roles asumidos por hombres y mujeres en tareas de subsistencia y movilidad. De esta manera se argumenta la existencia de diferencias en las estructuras sociales entre ambas sociedades fueguinas, a partir de la manipulación de materiales y conocimientos necesarios para la producción y uso de las pinturas.
\end{abstract}

Palabras claves: Selk’nam, Yamana, pinturas corporales, usos, diseños, diferencias inter-sociedad, divisiones intrasociedad.

In this introduction to the uses of body painting by the Selk'nam and the Yamana from Tierra del Fuego, I describe the sources of data for these practices (photographs and written texts) and their organization and study. Also explained are the methods used to assess their accuracy, reliability and relevance. The general aim of the paper is to search for similarities and differences in the uses of body painting by both societies in order to analize the social dynamics identified, particularly in relation to gender divisions, which context is related to the contents of some myths, and to roles played by men and women in subsistence and mobility tasks. To this end, we developed quantitative analyzes of some aspects related to their use (such as the gender, age and body portions painted on each photographed individual), as well as an analysis of formal factors of the paintings (their techniques and designs), and qualitative analyzes of processes implicit in the use of the paintings. It is suggested that the existence of differences in the social structures of each Fuegian group can be seen in the manipulation of materials and knowledge about the production and use of body paintings.

Key words: Selk'nam, Yamana, body paintings, painted designs, inter-society differences, gender, intra-society divisions.

La existencia de sociedades cazadoras-recolectoras con modos de vida terrestres y marítimos en Tierra del Fuego es un hecho bien conocido en el mundo académico. Éstas han sido y son objeto de estudios arqueológicos, antropológicos e históricos (entre otros) que han ido develando la riqueza y complejidad de varios aspectos de su desarrollo, tales como su subsistencia, tecnología, organización familiar, mitos, creencias, ceremonias, etc. (Bridges 1897; Fitz-Roy 1839; Gusinde 1982, 1986; Hyades y Deniker 1981; Lis- ta 1887; Lothrop 1928; entre otros). Pese a que las fuentes históricas y etnográficas revelan que las sociedades fueguinas Selk'nam, Yamana, Alacaluf y Haush creaban y utilizaban pinturas corporales, éstas no han sido sujetas a estudios específicos y sistemáticos de la misma magnitud que los mencionados anteriormente. El objetivo de este trabajo es presentar resultados obtenidos del estudio visual y contextual de las pinturas de los grupos Selk'nam y Yamana, a manera de introducción.

* CONICET (Consejo Nacional de Investigaciones Científicas y Técnicas, Argentina), AIA (Asociación de Investigaciones Antropológicas). Rivadavia 137911 “F” C.P. (1033) Buenos Aires, Argentina. danae_fiore@yahoo.es; danae_fiore@ Argentina.com 
Debido a la extensión de la información, se presentará un panorama sintético acerca de los diseños, técnicas, sexo y edad de las personas pintadas, y situaciones de uso de las pinturas. Dentro de estas últimas, se hará referencia a las pinturas ceremoniales para presentar algunos puntos relevantes de las dinámicas sociales implicadas en su uso.

Se demostrará que las prácticas de pintura corporal tuvieron un papel activo y fundamental en la construcción del mundo social Selk'nam y Yamana; la discusión se centrará en la búsqueda de semejanzas y diferencias en la producción y el uso de pinturas. Estas sociedades diferían considerablemente en cuanto a sus modos de vida: los Selk'nam eran primordialmente cazadores-recolectores pedestres y los Yamana cazadores-recolectores marítimos (Figura 1). Esto implicaba distintos tipos de movilidad y subsistencia, así como tecnologías específicas adecuadas a la explotación de recursos de tierra (p. ej., guanacos) y de mar (p. ej., pinnípedos y peces). Estas tecnologías (proyectiles, arpones, redes, canastas, etc.) eran básicamente conocidas por ambas sociedades, aunque desarrolladas y utilizadas con distinta variedad e intensidad (Massone 1989; Ortiz Troncoso 1989; Orquera y Piana 1999). Partiendo de esta base, nos planteamos la pregunta si existían también diferencias en cuanto a las técnicas, diseños y usos de pinturas corporales. De encontrarse estas diferencias, podrían estar vinculadas a: (1) factores internos a la producción de pinturas (p. ej., disponibilidad de materias primas, desarrollo de tecnologías-instrumentos, gestos técnicos, conocimientos, procedimientos de producción y aplicación de pintura), y (2) factores contextuales que relacionaran la producción de pinturas con otras actividades en cada sociedad. En este último caso, podrían existir diferencias en los roles asumidos por hombres y mujeres en la producción y el uso de las pinturas en cada sociedad, y que éstas podrían estar vinculadas con las distintas divisiones sexuales del trabajo en tareas de subsistencia y movilidad de los sistemas socioeconómicos Selk'nam y Yamana. Asimismo, se exploró la expectativa de que las prácticas de pintura corporal de cada grupo estuvieran en consonancia con el contenido de algunos de los mitos producidos por cada sociedad.

\section{Fuentes de Datos y Métodos de Análisis}

\section{Fuentes de información}

La existencia de pigmentos en sitios arqueológicos de Tierra del Fuego ha sido documentada

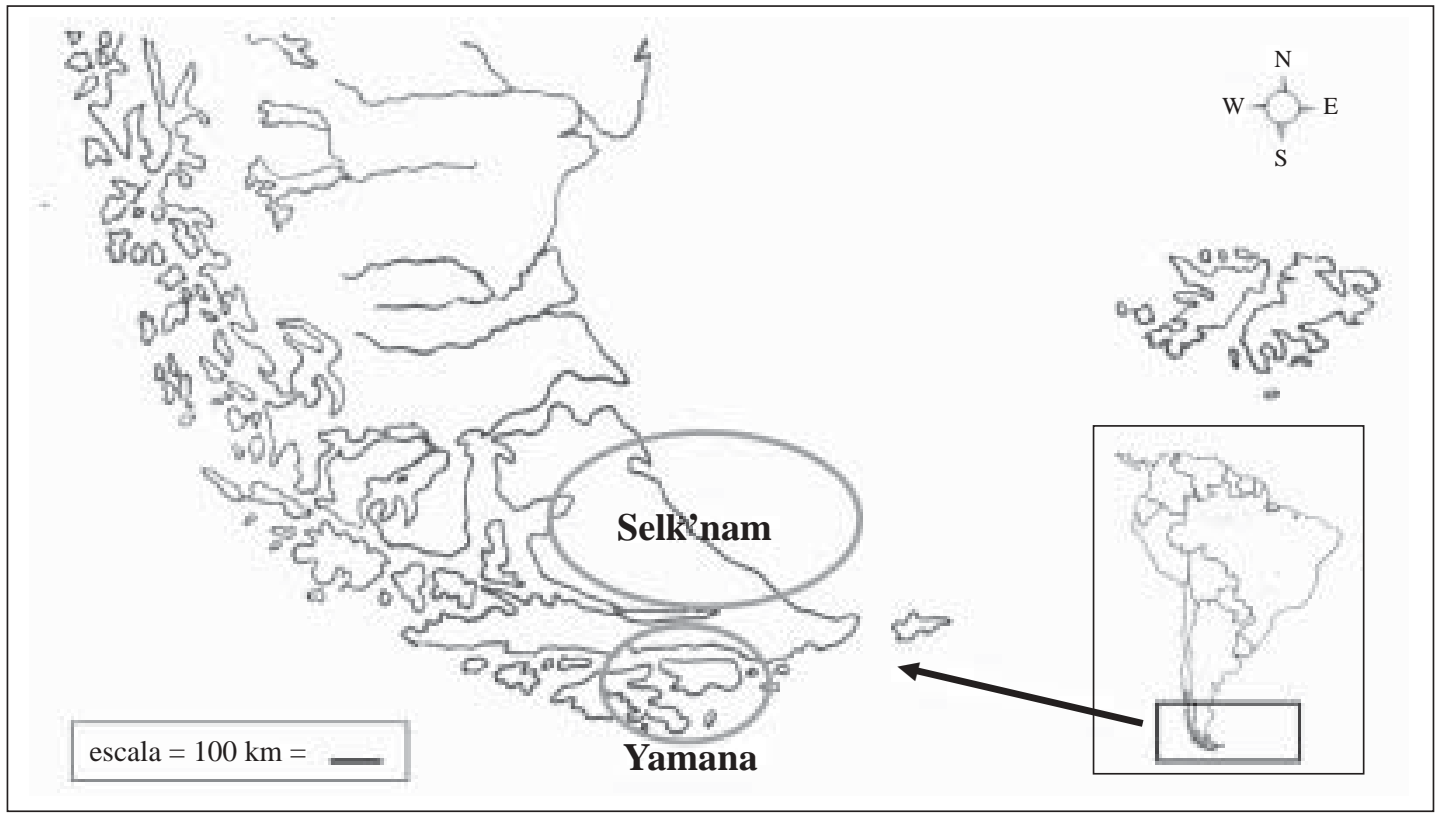

Figura 1. Mapa de territorios de grupos Selk'nam y Yamana de Tierra del Fuego.

Map of Selk'nam and Yamana territories in Tierra del Fuego. 
en varios yacimientos, entre otros Túnel I, Shamakush I, Imiwaia I (Orquera y Piana 1999) y Tres Arroyos (Massone 1989). Sin embargo, este material es ambiguo en cuanto a su potencial funcionalidad, ya que las sustancias colorantes pueden haber sido utilizadas para decorar objetos (p.ej., tabletas de madera) o tratar materias primas (p.ej., cueros). Es por ello que no pueden considerarse como evidencia directa de la producción y uso de pinturas corporales. Tampoco se han identificado de manera fehaciente instrumentos para pintar (como veremos, muchas veces las pinturas se realizaban solamente empleando las manos como instrumento aplicador de pintura). Por esta razón, la investigación sobre la que se basa este trabajo se centra en información obtenida a partir de dos fuentes: textos escritos y documentos gráficos (fotografías y dibujos), generados por viajeros, misioneros y etnógrafos que visitaron la región entre los siglos XVI y XX.

De esta manera, se identificaron 75 fuentes de primera mano escritas por 52 autores que registran información acerca del uso de pinturas corporales por grupos Selk'nam, Yamana o ambos. Tales fuentes varían considerablemente en el nivel de detalle, incluyendo desde breves menciones hasta detallados registros. Los documentos gráficos suman 228 (130 relativos a los Selk'nam y 98 a los Yamana), sumando un total de 449 individuos ${ }^{1}$. Éstos incluyen en su mayoría fotografías de personas pintadas, dibujos de personas pintadas, y algunas fotografías y dibujos de materiales para realizar las pinturas. Todos los textos (a excepción de uno) y todos los documentos gráficos sobre los que se basó esta investigación se encuentran publicados. En las referencias citadas se incluye una lista no exhaustiva de estas publicaciones.

\section{Métodos de trabajo}

Con el objeto de evaluar críticamente las circunstancias en las cuales se registró la información incluida en los textos, se analizó cada uno de éstos de acuerdo a los siguientes criterios: (1) fechas de viaje/estadía del autor del texto y fechas de las observaciones; (2) nacionalidad; (3) misión, barco, etc.; (4) cantidad de tiempo en contacto con los Fueguinos; (5) identificación "étnica" del grupo social Fueguino realizada por el/los autores; (6) ubicación geográfica precisa de las observaciones;
(7) edad y sexo de los informantes (cuando los hubo); (8) lenguaje en el que se comunicaban observadores y nativos; (9) propósitos y puntos de vista de los viajeros-misioneros-etnógrafos (sesgos teóricos e ideológicos); (10) sexo del observador; (11) fecha de publicación del texto o documento gráfico; (12) cambios entre versiones de un mismo texto o imagen en distintas publicaciones; (13) variaciones entre distintas publicaciones de un mismo autor.

De esta manera, se buscó evaluar la confiabilidad, relevancia y nivel de detalle de las fuentes, procurando contextualizar el registro de la información de acuerdo a los intereses y sesgos del observador/autor del texto. Esto permitió identificar distintas tendencias valorativas en la descripción, apreciación e interpretación del uso de pinturas por los Fueguinos, incluyendo su descripción como salvajes sucios, criaturas exóticas, personas lamentables que debían ser aculturadas, o casos etnográficos que debían ser registrados antes de su extinción (casos que han sido detalladamente discutidos en trabajos previos: Fiore 2002, 2004a). Identificar estos sesgos no implica la posibilidad de deshacerse de la subjetividad inherente a estos textos, pero permite reconocer la perspectiva desde la cual la información fue registrada y las interpretaciones construidas. Además, los contenidos de los textos fueron comparados entre sí para verificar si se corroboran, completan o contradicen, lo cual contribuye a la evaluación de la consistencia de la información.

Los datos obtenidos en relación a la producción y usos de las pinturas fueron registrados sistemáticamente considerando las siguientes variables: (1) materiales y técnicas de producción y aplicación de pintura; (2) tipos de situación en los que se observó la producción y el uso de pinturas (cotidiano, ceremonial); (3) roles, edad y sexo de los usuarios de las pinturas; (4) porciones del cuerpo que se registran como pintadas; (5) colores; (6) diseños (compuestos por uno o más motivos); (7) significado de colores y/o de diseños (si es que lo tenían).

Con respecto a la documentación gráfica (fotografías y dibujos), se realizó una base de datos registrando las siguientes variables (se indican sólo las principales): autor, fecha, fecha de publicación, publicación/es, epígrafe/s, visibilidad de la fotografía, cantidad de personas fotografiadas (sexo y 
edad), cantidad de personas pintadas (sexo y edad), situación de uso de pinturas, etc.

Esta base de datos permitió el registro y análisis de la información relativa a las fotografías y dibujos, su contexto de producción, edición y publicación. De esta manera se identificaron sesgos en las tomas y edición de las fotografías, relativos tanto a los fotógrafos como a los sujetos fotografiados (discutidos en Fiore 2002, 2004b). Un ejemplo de sesgo en las tomas es el registrado en una fotografía de De Agostini (1945:67) que representa a dos mujeres Yamana (Yayosh y Lakutaia Le Kipa, también conocida como Rosa Yagan) vestidas con pieles de guanaco al estilo Selk'nam. Sin embargo, hemos identificado que la pintura facial que lleva Lakutaia Le Kipa corresponde a un diseño Yamana (Fiore 2002:564$565)$. Esto sugiere que el fotógrafo no habría interferido sobre esta práctica para tomar la fotografía, e indica, a su vez, que no siempre los sesgos del registro fotográfico son totales; esto permite realizar inferencias no solamente acerca de los intereses y perspectivas de los fotógrafos, sino también acerca de características y actitudes de los sujetos fotografiados.

Un ejemplo de sesgo en la edición de fotografías es la forma de edición y publicación de una toma de un grupo Selk'nam en el libro "Los Onas" de Gallardo (1910), que fue fragmentada en nueve recortes y utilizada para ilustrar distintas páginas del libro sin indicar que todos esos recortes pertenecen a una misma fotografía (aunque en algunos casos se consignaron en los epígrafes los nombres de las personas retratadas). $\mathrm{La}$ fotografía completa fue publicada por Barclay (1926:216-217), quien viajó con Gallardo a Tierra del Fuego en 1904. Estos usos de una misma fotografía ejemplifican la diferencia entre el tratamiento de la foto principalmente como ilustración versus como documento, y señala también la relevancia de realizar búsquedas y comparaciones entre distintas publicaciones (y si es posible la comparación con los negativos o copias originales), con el objeto de identificar sesgos en la edición de estos documentos que marcan potenciales transformaciones de la información registrada y así resultan informativos de los intereses de los autores y editores (Collier 1975; Prieto y Cárdenas 1997; Scherer 1992; entre otros).

En una segunda base de datos se registraron variables relativas a cada individuo pintado, inclu- yendo: situación de uso de pinturas (cotidiana o ceremonial), parte visible del cuerpo, sexo, edad y rol del usuario, porción/es del cuerpo pintadas, técnica/s de pintura, tipo, color, posición y orientación de motivos, principios visuales y simetría del diseño, uso de máscaras, artefactos, ornamentos y ropa. Mediante esta base de datos se realizó el análisis sistemático cualitativo y cuantitativo de los usos de las pinturas, según sexo, edad, situación, etc., así como de sus diseños y técnicas, lo que permitió identificar patrones formales de los diseños y tendencias en su uso en situaciones específicas. A continuación presentaremos algunos de los resultados obtenidos.

\section{Personas, Técnicas y Diseños. Un Panorama Cuantitativo}

\section{Técnicas y diseños. Una visión comparativa}

Las pinturas eran realizadas por ambas sociedades con los mismos colores: rojo, blanco y negro $^{2}$. Esta similitud tiene una doble implicación; por un lado, se relaciona con la disponibilidad de materias primas y las posibilidades técnicas de procesarlas para lograr dichos colores. Las sustancias colorantes básicamente empleadas para lograr el rojo eran arcilla, ocre y sangre; para el blanco eran limo y arcilla, y para el negro, carbón y cenizas (existen algunas variaciones en cada sociedad, que no discutiremos en este trabajo). Las formas de procesamiento eran similares en ambas sociedades, e incluyen el raspado, molido/triturado/pulverizado, masticado, quemado, y mezcla con agua, saliva, aceite o grasa. Por otro lado, dentro de estas limitaciones de disponibilidad y tecnología, el hecho de que ambas sociedades hayan usado los tres colores indica una selección estética, ya que, dentro de este rango de colores disponibles, podrían haber prescindido de alguno ${ }^{3}$.

De acuerdo a las fuentes escritas, las técnicas de pintura corporal empleadas por los Selk'nam eran: (1) frotamiento de pintura con la mano sobre la piel; (2) pintura escupida sobre la piel y luego frotada con la mano; (3) aplicación de pintura con un dedo; (4) aplicación de pintura con un palillo, espátula o instrumento tipo "peine"; (5) aplicación de líneas positivas presionando la palma de la mano contra la piel, habiendo previamente cubierto la palma con pintura y eliminado líneas negativas con los dedos/uñas; (6) aplicación de pintura sobre la 
piel y remoción de parte de ella con dedos/uñas, dejando líneas en negativo sobre la piel y líneas de pintura en positivo; (7) aplicación de bollitos de plumón sobre la piel (técnica de ornamentación corporal que era combinada con la pintura).

Debido a la dificultad de identificar algunas de estas técnicas mediante la observación de fotografías, se las ha identificado tomando en cuenta las características visuales que generaría cada una. Para ello, se han agrupado las que son similares y, por lo tanto, no distinguibles entre sí en las fotografías (p. ej., técnica 1+2, 3+4; Tabla 1).

Las técnicas registradas como las más frecuentemente usadas son la $3+4$, seguidas por la $1+2$. Esto indica una preferencia hacia los diseños relativamente detallados, que la técnica $3+4$ permitía generar, mientras que la técnica $1+2$ era más apropiada para producir diseños de mayor tamaño y menor detalle, y fondos base de color sobre los cuales producir diseños más detallados. Las técnicas 5, 6 y 7 eran muy infrecuentes. La técnica 5 era empleada solamente por individuos desempeñando el rol de xons (chamanes). La técnica 7 era utilizada en la ceremonia del hain (ver más adelante); cuando ésta fue observada por Gusinde en 1923 era utilizada para decorar individuos que desempeñaban los roles de los espíritus Tanu y K'terrnen (Gusinde 1982), mientras que Bridges (1935) habría observado también su uso para el espíritu So'orte. Los textos indican que los Yamana utilizaban las técnicas de pintura corporal 1, 2, 3, 4 y 6 (Tabla 2 ). Esto marca inicialmente una diferencia con el caso Selk'nam, en el que también se registraron las técnicas 5 y 7 .

La técnica más frecuentemente utilizada por los Yamana era la 3+4, seguida por la combinación entre $1+2$ y $3+4$. La técnica $1+2$ no era frecuentemente usada sin combinación. Esto indica una tendencia de los Yamana a no producir diseños que consistieran únicamente en bases o formas grandes de color, sino a emplearlas en combinación con elementos más detallados. Esto marca una diferencia con el caso Selk'nam, que se confirma estadísticamente $\left(\mathrm{X}^{2}=47, \mathrm{df}=2,99 \%\right.$ de nivel de confianza), y marca la tendencia de la sociedad Yamana a usar más la técnica $3+4$ y $1+2$ combinada con $3+4$ con una frecuencia mayor a la estadísticamente esperada, si ello hubiera ocurrido al azar. Esta diferencia puede deberse a tendencias estilísticas distintas en ambas sociedades o a las funciones que
Tabla 1. Selk'nam: combinación de técnicas de pintura corporal (sólo casos alta visibilidad). Selk'nam: body painting techniques (only high visibility cases).

\begin{tabular}{lc}
\hline Técnicas & Individuos \\
\hline $1+2$ & 35 \\
$1+2$ y $3+4$ & 9 \\
$1+2$ y $3+4$ y 7 & 2 \\
$1+2$ y $3+5+6$ & 2 \\
$3+4$ & 81 \\
$3+4+5+6$ & 1 \\
\hline Total & 130 \\
\hline
\end{tabular}

Tabla 2. Yamana: combinación de técnicas de pintura corporal (sólo casos alta visibilidad). Yamana: body painting techniques (only high visibility cases).

\begin{tabular}{lc}
\hline Técnicas & Individuos \\
\hline $1+2$ & 9 \\
$1+2$ y $3+4$ & 51 \\
$3+4$ & 63 \\
\hline Total & 123 \\
\hline
\end{tabular}

cumplían los diseños elaborados con las técnicas antes descritas. La técnica $1+2$ permite cubrir porciones más amplias del cuerpo (con menos detalle e inversión laboral), lo cual generaba diseños de alta visibilidad a mayor distancia. Esto era necesario especialmente en el caso de la presentación de los espíritus Selk'nam del hain y Yamana del kina, que debían ser vistos y reconocidos desde distancias considerables (ver más adelante). En tal caso, el mayor uso de la técnica $1+2$ sin combinación registrada en el caso Selk'nam pudo deberse, en parte, a la mayor cantidad disponible de fotografías de espíritus del hain (43 fotos) en comparación con las del kina Yamana (10 fotos). Sin embargo, los diseños de los espíritus del kina incluían elementos producidos con la técnica $1+2$, pero combinados con otros correspondientes a la técnica $3+4$; esto sugiere que, más allá de un sesgo en el registro por diferencias en los tamaños de las muestras, las diferencias podrían surgir también de distintas tendencias estilísticas en la construcción técnico-visual de los diseños. 
Los diseños Selk'nam varían desde algunos muy simples, constituidos por un único elemento básico (p. ej., una línea en cada mejilla), hasta otros complejos, construidos mediante la combinación de varios elementos de diferentes tamaños, orientaciones, colores y posiciones. Se ha identificado un total de 49 motivos construidos a partir de 13 elementos básicos, solos o combinados. El más frecuente era la línea, seguida por las bases de color y los puntos (Tabla 3).

Los diseños Yamana presentan una cierta variedad, registrados algunos en varias oportunidades y otros fotografiados en una única ocasión. Se ha identificado un repertorio de 33 motivos empleados por individuos de esta sociedad. Éstos eran usados solos o combinados, formando diseños de distinto nivel de complejidad. Los motivos eran construidos mediante el uso individual o combinado de los elementos básicos listados en la Tabla 3. El elemento más frecuente en los motivos Yamana era la línea, seguida por las bases de color; en tercer lugar se ubican las hileras de puntos. La considerable frecuencia del uso de bases de color en ambas sociedades se debe, en parte, a que éstos operaban en muchas ocasiones como "fondos" sobre los cuales se pintaban otros diseños más detallados. Estas bases se realizaban con las técnicas 1 ó 2, de ahí su alta frecuencia en ambas sociedades.
Si se comparan los elementos usados en los motivos Selk'nam y Yamana, cada sociedad usaba 13 de un total de 16, y había 10 en común. Sin embargo, los motivos resultantes construidos con estos elementos eran distintos, ya que de los 49 motivos Selk'nam y 33 Yamana, solamente se identificaron 9 en común. Esto marca una profunda independencia creativa en las tradiciones visuales de cada sociedad. Además, los elementos decorativos específicos de cada sociedad se usaban para construir motivos empleados en situaciones particulares, por personas que desempeñaban roles específicos. Las líneas irregulares aparecen en diseños faciales Selk'nam mayormente usados por xons (chamanes) y por jóvenes que eran iniciados a la adultez en el hain; su producción requiere el uso de la técnica 5, que era sólo usada por esta sociedad. Las hileras de puntos grandes usualmente aparecen en los diseños Selk'nam de los espíritus del hain y no se observan en pinturas Yamana. Las hileras de guiones consecutivos aparecen en diseños Yamana de espíritus del kina (ceremonia de iniciación masculina), y son particulares de esta ceremonia y esta sociedad. Las líneas de dos colores eran usadas con poca frecuencia por los Yamana: se registran solamente en algunas pinturas del chiéjaus (ceremonia de iniciación mixta) y en una de duelo. Los bollitos de plumón eran usados por los Selk'nam para decorar el cuerpo de K'terrnen, un

Tabla 3. Selk'nam y Yamana: elementos básicos para construir motivos de pintura corporal. Selk'nam and Yamana: basic elements used to create body painting motifs.

\begin{tabular}{|c|c|c|c|c|}
\hline \multicolumn{2}{|c|}{ Tipos de elementos decorativos } & \multirow{2}{*}{$\begin{array}{c}\text { Selk'nam } \\
\text { Sí }\end{array}$} & \multirow{2}{*}{$\begin{array}{c}\text { Yámana } \\
\text { Sí }\end{array}$} & \multirow[t]{2}{*}{ Elementos decorativos } \\
\hline BA & - bandas & & & \\
\hline $\mathrm{BD}$ & - puntos grandes & Sí & Sí & \\
\hline $\mathrm{CB}$ & - bollitos de plumón & Sí & No & \\
\hline DCL & - líneas de dos colores & No & Sí & \\
\hline $\mathrm{DCL} / \mathrm{RD}$ & - líneas de dos colores e hileras de puntos & No & Sí & \\
\hline DS & - guiones & Sí & Sí & \\
\hline DT & - puntos & Sí & Sí & \\
\hline GR & - fondos de color & Sí & Sí & (ver Figuras 4 y 7 ) \\
\hline IS & - líneas irregulares & Sí & No & \\
\hline LI & - líneas & Sí & Sí & \\
\hline $\mathrm{LI} / \mathrm{RD}$ & _ hileras de puntos combinadas con líneas & Sí & Sí & \\
\hline PT & _ "parches" (porciones semi-rectangulares u ovaladas) & Sí & Sí & \\
\hline RBD & _ hileras de puntos grandes & Sí & No & \\
\hline $\mathrm{RD}$ & - hileras de puntos & Sí & Sí & \\
\hline RCDS & - hileras de guiones consecutivos & No & Sí & \\
\hline RPDS & - hileras de guiones paralelos & Sí & Sí & \\
\hline \multicolumn{2}{|c|}{ Total de 16 elementos básicos } & 13 & 13 & \\
\hline
\end{tabular}


bebé mítico representado por un iniciando en el hain, y la capa de Tanu, un espíritu de esta ceremonia. Su aplicación requiere la técnica 7 , exclusiva de esta sociedad.

\section{El Caso Selk'nam. Sexo, Edad y Porciones del Cuerpo Pintadas}

Tanto las fotografías como los textos indican que personas Selk'nam de todas las edades y de ambos sexos usaban pinturas corporales. Sin embargo, en todos los grupos de edad, los varones pintados que aparecen en las fotografías son muchos más que las mujeres (82\% contra $18 \%$, Tabla 4$)^{4}$. En ambos sexos, los individuos pintados más frecuentes son los adultos. Esto sugiere una predominancia de un género y un grupo de edad en el uso registrado de pinturas, que pudo estar influido por: (a) la actividad de uso de pinturas en sí; (b) el interés de los fotógrafos en registrar algunas pinturas en particular, como las de los "espíritus" del hain (que son todos individuos masculinos, ver más adelante); (c) alguna posible actitud de los Selk'nam con respecto a ser fotografiados, que restringiera la exposición de algunos grupos de sexo o edad. La asociación entre sexo y edad, marcada especialmente por la predominancia de hombres adultos, está confirmada por un test de $X^{2}\left(X^{2}=16.57, \mathrm{df}=3 \text {, nivel de confianza } 99 \%\right)^{5}$.

En cuanto a las porciones del cuerpo que eran pintadas, existen muchos más casos de mujeres usando pinturas faciales, que faciales más corporales, mientras que los hombres usaban pinturas en la cara y el cuerpo de manera más proporcional (Tabla 5). Esta asociación entre sexo y porciones del cuerpo pintadas se verifica estadísticamente $\left(X^{2}=13.89, \mathrm{df}=2\right.$, nivel de confianza $\left.99 \%\right)$.

Tabla 4. Selk'nam: edad y sexo de personas pintadas. Selk'nam: age and gender of painted persons.

\begin{tabular}{lrrr}
\hline \multirow{2}{*}{ Edad } & \multicolumn{2}{c}{ Sexo } & \\
\cline { 2 - 4 } & F & M & Total \\
\hline adultos & 17 & 75 & 92 \\
bebés & & 3 & 3 \\
niños & 6 & 13 & 19 \\
no det. (adult. enmasc.) & & 34 & 34 \\
ancianos & 1 & 5 & 6 \\
jóvenes & 6 & 7 & 13 \\
\hline Total & 30 & 137 & 167 \\
\hline
\end{tabular}

Tabla 5. Selk'nam: sexo y porciones del cuerpo de personas pintadas.

Selk'nam: gender and painted body portions.

\begin{tabular}{lrrr}
\hline & \multicolumn{2}{c}{ Sexo } & \\
\cline { 2 - 4 } Edad & F & M & Total \\
\hline cuerpo & 1 & 29 & 30 \\
cara & 24 & 59 & 83 \\
cara + cuerpo & 5 & 49 & 54 \\
\hline Total & 30 & 137 & 167 \\
\hline
\end{tabular}

Esto puede reflejar una decisión de los fotógrafos occidentales, quienes pueden haber elegido no fotografiar tantas mujeres con pinturas sobre el cuerpo, aunque desconocemos las razones de tal potencial decisión. El reparo a exhibirse desnudos puede haber surgido por influencia de misioneros y colonizadores occidentales, aunque también puede haberse originado parcialmente en momentos precontacto. Aunque los Selk'nam adoptaron la vestimenta occidental, en los inicios del siglo XX aún usaban sus vestimentas "tradicionales" espontáneamente en algunos casos, o a pedido de los fotógrafos (a veces con objeciones) en otros casos (Dabbene 1911; Gusinde 1982). En todas las fotos de Selk'nam pintados que hemos registrado, éstos aparecen usando vestimentas "tradicionales" y en todos los casos son claras las diferencias de sexo en las porciones del cuerpo que eran pintadas. Por lo tanto, pese a que la aculturación occidental puede haber influido en las diferencias de género observadas, es también posible que dicha tendencia se basara -por lo menos en parte- en patrones culturales propios de los Selk'nam.

\section{El Caso Yamana. Sexo, Edad y Porciones del Cuerpo Pintadas}

De acuerdo con la información escrita y visual, los Yamana de ambos sexos y de todas las edades (excepto bebés) usaban pinturas corporales. La Tabla 6 muestra la edad y sexo de las personas pintadas registradas en fotografías e indica que las frecuencias de individuos masculinos $(55,8 \%)$ y femeninos $(44,2 \%)$ usando pinturas son bastante similares. Esto contrasta con el caso Selk'nam, en el que se registra una predominancia masculina. Tanto en los casos femeninos como masculinos, las frecuencias más altas se encuentran en la categoría de edad adulta, lo cual marca una simili- 
Tabla 6. Yamana: edad y sexo de personas pintadas. Yamana: age and gender of painted persons.

\begin{tabular}{lrrr}
\hline \multirow{2}{*}{ Edad } & \multicolumn{2}{c}{ Sexo } & \\
\cline { 2 - 4 } & F & M & Total \\
\hline adultos & 39 & 49 & 88 \\
niños & 7 & 14 & 21 \\
no det. (adult. enmasc.) & & 9 & 9 \\
ancianos & 8 & 5 & 13 \\
jóvenes & 15 & 10 & 25 \\
\hline Total & 69 & 87 & 156 \\
\hline
\end{tabular}

tud con el caso Selk'nam. Sin embargo, en el caso Yamana no existe una asociación estadísticamente significativa entre sexo y edad, lo cual marca la distribución pareja de edades en ambos sexos $\left(\mathrm{X}^{2}=\right.$ 4.63, $\mathrm{df}=3$, nivel de confianza $99 \%$ ).

También existe similitud entre los casos Selk'nam y Yamana en cuanto al ranking de edades en términos de sus frecuencias: en ambos casos los adultos son seguidos por los niños, luego los jóvenes y finalmente los ancianos (y los bebés sólo en el caso Selk'nam). Esto sugiere que en ambas sociedades el uso de pinturas corporales era primariamente llevado a cabo por los adultos y/o que éstos eran más fotografiados.

Existen muchos más casos de mujeres usando pinturas faciales que faciales más corporales, mientras que los hombres usaban pinturas en cara y cuerpo de manera más proporcional (Tabla 7). Las fotos tempranas (siglo XIX) de los Yamana muestran tanto a hombres como a mujeres con sus vestimentas "tradicionales", que dejaban gran parte del cuerpo desnudo. Bajo la influencia de los misioneros, los Yamana comenzaron a usar vestimenta occidental. Esto claramente restringió las zonas del cuerpo que podían ser pintadas. Sin embargo, las diferencias de sexo no pueden ser atribuidas a la vestimenta occidental, sino que ocurrían a través de su uso. Cuando las mujeres Yamana usaban pinturas en su cuerpo, estas cubrían sus brazos, muy esporádicamente la parte superior del tronco (tres casos) y solamente en un caso las pantorrillas, pero no sus troncos ni muslos, que permanecían cubiertos con vestimenta. En cambio, los hombres se pintaban los troncos (quitándose la camisa) y las piernas (arrollándose los pantalones). La influencia occidental cambió también la forma en que los hombres Yamana usaban las pinturas, ya que en ninguna de las fotos aparecen con sus muslos, ca-
Tabla 7. Yamana: sexo y porciones del cuerpo de personas pintadas.

Yamana: gender and painted body portions.

\begin{tabular}{lrrr}
\hline & \multicolumn{2}{c}{ Sexo } & \\
\cline { 2 - 3 } Edad & F & M & Total \\
\hline cuerpo & & 1 & 1 \\
cara & 58 & 53 & 111 \\
cara + cuerpo & 11 & 33 & 44 \\
\hline total & 69 & 87 & 156 \\
\hline
\end{tabular}

deras o genitales pintados (como sí lo hacían los hombres Selk'nam), sino con los pantalones arrollados o trozos de lienzo cubriendo sus pelvis. Esto sugiere que el impacto de la aculturación en ambas sociedades fue muy distinto, ya que, aunque ambas fueron forzadas a adoptar la vestimenta occidental, los hombres Selk'nam retornarían a sus costumbres de pintarse el cuerpo entero, mientras que los Yamana no. Estas diferencias entre ambas sociedades quedan aún más evidenciadas cuando se tiene en cuenta que la información visual que se está comparando proviene de los mismos fotógrafos, con lo cual incluso si éstos tenían sesgos respecto de la desnudez y/o de las formas de pintarse de los fueguinos, los grupos Selk'nam y Yamana no negociaban estas situaciones de la misma manera.

\section{Las Pinturas Selk'nam. Usos e Implicaciones Sociales}

Los Selk'nam utilizaban pinturas corporales durante distintas situaciones de su vida cotidiana y en ocasiones especiales. Las primeras incluyen: la expresión de estados de ánimo, el embellecimiento, la realización de visitas y viajes, la cacería (incluyendo el camuflaje), los combates o luchas y la protección de la piel (Beauvoir 1915:206; Bridges 1951:367; De Agostini 1924:276; Gallardo 1910:152; Gusinde 1982:208-209 y 1101-1102; Lista 1887:101; entre otros; Figura 2). Las ocasiones especiales incluyen: el nacimiento, la primera menstruación, el "compromiso" entre novios, el casamiento, la pintura de los xons (chamanes), el duelo y el hain o ceremonia de iniciación masculina (Beauvoir 1915:208, 290; Bridges 1951:364; De Agostini 1924:283; Gusinde 1951, 1982:310-311; Koppers 1991:39; Lista 1887:92-93; Segers 1891:69; entre otros). 


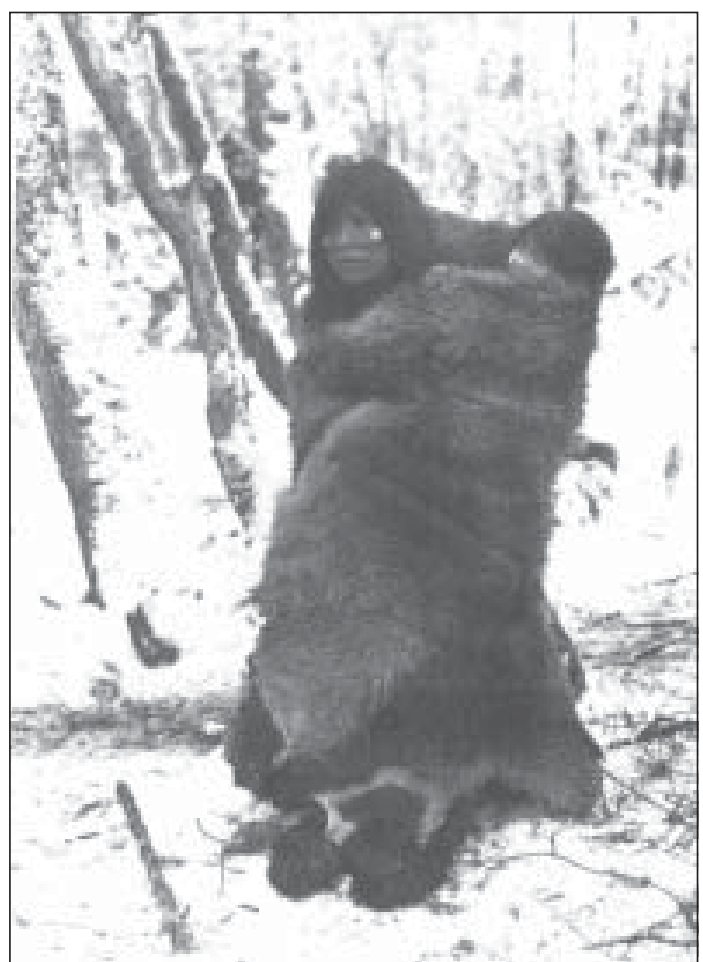

Figura 2. Mujer Selk'nam con pintura facial de aparente uso cotidiano (foto tomada por Gusinde en 1918-1922 y publicada por Gusinde 1989 [1939], apéndice II, pp. 601, figura 40).

Selk' nam woman wearing facial paintings, apparently worn in everyday situations (photo taken by Gusinde in 1918-1922 and published by Gusinde 1989 [1939], appendix II, pp. 601, figure 40).

Algunos de estos usos eran netamente prácticos y no parecen haber incluido una construcción visual de diseños sobre el cuerpo. Tales son los casos (aunque poco documentados) de aplicación de sedimentos arcillosos sobre el cuerpo, con el objeto de proteger la piel del clima, y de frotación de éstos sobre el cuerpo para limpiarlo (Barclay 1924:14; Gusinde 1982:206; Lothrop 1928:58-59).

Pero la mayoría de los usos de pinturas corporales implicaba la creación de diseños visuales usando un motivo o combinando varios. Algunos de estos diseños eran representativos de referentes (materiales y/o conceptuales), mientras que otros no representaban un referente externo. Un ejemplo de estos últimos es el uso de un motivo compuesto de tres puntos blancos, dos de ellos ubicados en las sienes y uno ubicado en el entrecejo, que hemos identificado como utilizado exclusivamente por los xons, tanto en fotografías como en un texto (ver fotos en

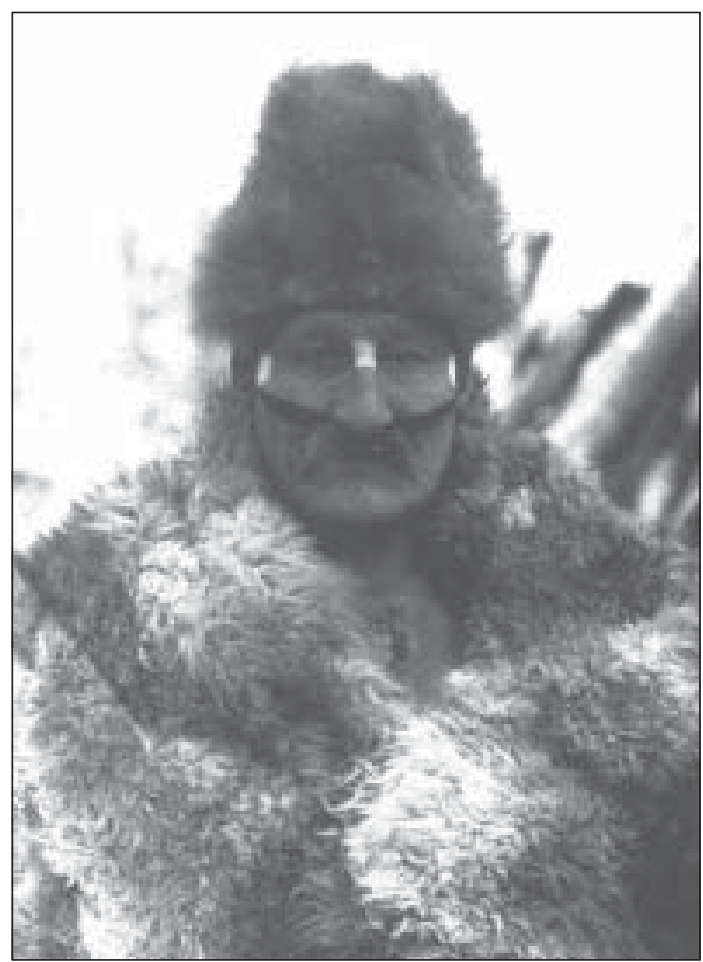

Figura 3. Tenenesk, hombre Selk'nam con pintura facial indicando su rol de xon (foto tomada por Gusinde en 1918-1922 y publicada por Gusinde 1989 [1939], apéndice II, pp. 663, figura 117).

Tenenesk, Selk'nam man wearing facial paintings indicating his role as xon (photo taken by Gusinde in 1918-1922 and published by Gusinde 1989 [1939], appendix II, pp. 663, figure 117).

Gusinde 1989:663 Figuras 116 y 117, descripción en Segers 1891:65 y Figura 3).

Esta pintura facial era indicativa del rol desempeñado por el hombre, pero no hay evidencias de que tuviera algún significado relativo a algún referente (haciendo alusión icónica o no-icónicamente a algún objeto o idea). Es interesante notar que no es la cantidad ni el color de los puntos, sino su posición la que define que éste fuera un motivo indicativo de este rol, ya que el mismo con los puntos ubicados sobre las mejillas ha sido registrado en otros individuos Selk'nam que no eran xons. Además, éste podía ser combinado con otros elementos, tales como una línea horizontal en cada mejilla, o una serie de líneas verticales irregulares aplicadas en la mitad inferior de la cara, dando lugar a otro motivo más complejo. Estos motivos "agregados" no parecen haber alterado la función indicativa del rol de xon desempeñado, ni tampoco eran exclusivos de estos individuos. Desde un punto de vista metodoló- 
gico, este caso manifiesta la importancia de registrar todas las variables que caracterizan a los diseños por separado, para seguirlas individualmente en la búsqueda de posibles patrones como el aquí comentado.

En otros casos, motivos y diseños eran no solamente indicativos de roles sociales, sino altamente significativos en tanto representaban un referente material o conceptual. Tal es el caso de muchas de las pinturas creadas durante el hain. Esta ceremonia de iniciación masculina a la adultez fue observada y documentada en 1914 por un misionero salesiano (Belza 1974), por L. Bridges (1935, 1951), y principalmente por Gusinde (1951, 1982), quien la observó en 1923. Chapman (1982) aunque no presenció la ceremonia agregó valiosa información a partir de entrevistas a informantes ${ }^{6}$ y realizó un profundo análisis de las prácticas y creencias del hain.

La ceremonia del hain era sumamente compleja (ver los trabajos antes citados), incluyendo el uso de pintura corporal. El hain tenía el doble propósito de iniciar a los jóvenes varones (kloketen) a la adultez, así como de controlar a las mujeres mediante la representación de espíritus llevada a cabo por hombres ya iniciados, y kloketen que llevaban máscaras y tenían los cuerpos pintados. Estos se reunían en una gran choza ceremonial, donde se pintaban y enmascaraban. Realizaban sus apariciones frente a esta choza, ubicada a la vera de un bosque y frente a un claro, a unos 200 pasos del campamento doméstico, al cual también se acercaban en ocasiones (ver gráfico en Chapman 1982:81). Las mujeres y niños usualmente miraban las apariciones desde el campamento, y tenían expresamente vedado acercarse a la choza del hain. Esta exclusión tenía como propósito mantener el "secreto" de que los espíritus que aparecían no eran más que hombres pintados y enmascarados ${ }^{7}$. La transmisión de este "secreto" de los hombres adultos a los jóvenes constituía uno de los contenidos fundamentales de la iniciación. El mantenimiento de este "secreto" era tan importante para los varones Selk'nam, que algunos agredieron a Gusinde cuando intentó fotografiarlos mientras se pintaban aún sin sus máscaras, pues decían que, de caer las fotografías en manos de las mujeres, ellas descubrirían al "secreto" (Gusinde 1982:867-869).

Durante el hain se presentaba una serie de espíritus masculinos y femeninos ${ }^{8}$ de los cuales hemos identificado 14 que empleaban pinturas. La estructura general de sus pinturas consistía en un diseño específico que cubría el torso, abdomen, caderas, pelvis, muslos y parte superior de los brazos, mientras que los antebrazos y las pantorrillas eran pintados habitualmente de blanco. Cada diseño específico, consistente en motivos básicamente formados con líneas, puntos y bandas de colores ubicados en posiciones y orientaciones particulares, pintados sobre un fondo de color contrastante, y continuados en las máscaras, permitía la identificación visual de cada espíritu (Fiore 2002:350-391).

De esta manera, cada diseño permitía que el hombre que lo llevaba representara un espíritu. En algunos casos, la información disponible no alcanza para discernir si esta representación visual era arbitraria o si remitía a algún referente específico más allá del espíritu representado. Pero en otros casos el diseño en sí mismo representaba un referente. Tal es el caso de los espíritus denominados So'ort, fundamentales en el desarrollo de la ceremonia (posiblemente por ello mejor documentados). Existían siete So'ort principales, que correspondían a diferentes puntos cardinales de diferentes linajes de unidades exogámicas y territorios, los cuales, a su vez, estaban vinculados con los postes principales del hain (Chapman 1982:50-57). Los So'ort llevaban un diseño básico consistente en un fondo de color, al cual se le superponían grandes puntos blancos en el tronco y muslos y una faja blanca pintada en la máscara, sobre el área de los ojos (Figura 4). So'ort representaba a un chamán mítico, un ancestro que había sido transformado en una pequeña lechuza blanca: los grandes puntos y faja blancos representaban su plumaje. Esto sugiere que el diseño básico de este espíritu no solamente indicaba el rol de So'ort, sino que su motivo principal, tenía un significado y era representativo de un ser mítico, que en este caso tenía, además, una apariencia real (una lechuza). Esta representación se estructuraba de manera icónica, creando una imagen visual con semejanzas a la apariencia del referente al que representaba. El diseño básico de So'ort mostraba variaciones entre los distintos So'ort principales y secundarios. Estas variaciones -que no analizaremos aquí por razones de espacio- se generaban combinando distintos elementos básicos (puntos, líneas, bandas), sus colores y orientaciones (Fiore 2002:350-360).

La función de So'ort era la de controlar a las mujeres y mantenerlas dominadas mediante su aparición amenazante e incluso mediante el castigo a 


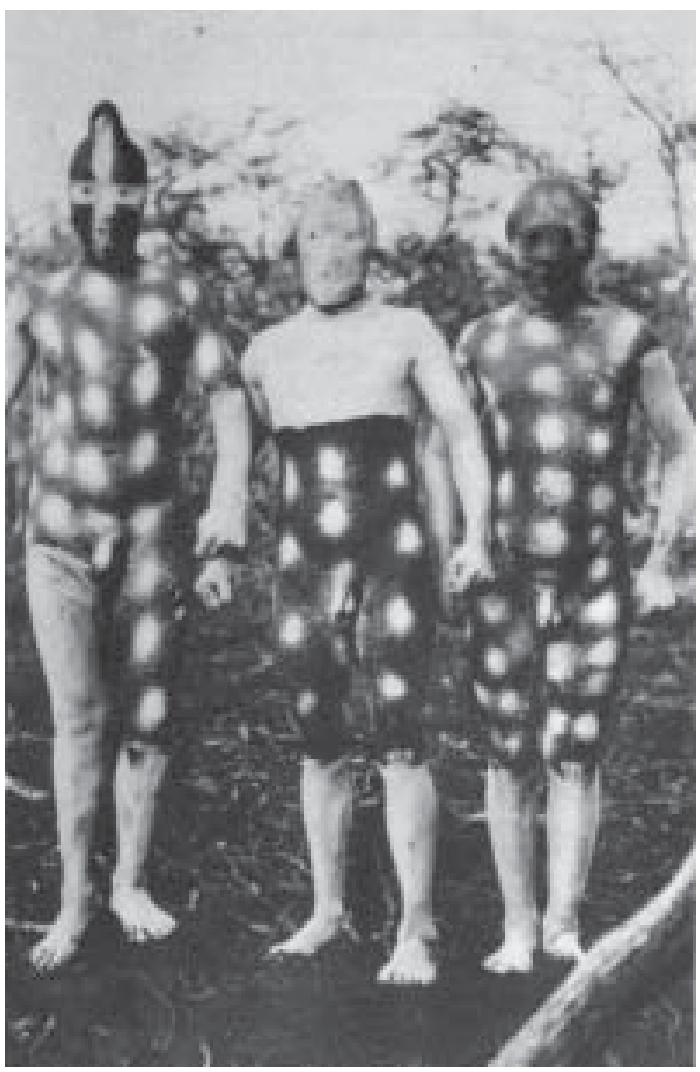

Figura 4. Tres espíritus So'ort subordinados durante la ceremonia del hain (foto tomada por Gusinde en 1923 y publicada por Gusinde 1989 [1939], apéndice II, pp. 631, figura 77).

Three subordinate So' orte spirits during the hain ceremony (photo taken by Gusinde in 1923 and published by Gusinde 1989 [1939], appendix II, pp. 631, figure 77).

las que habían sido "insubordinadas". Este era sugerido por sus maridos u otros hombres de la familia, arribando al campamento doméstico, sacudiendo las chozas y arrojando elementos fuera de éstas (Gusinde 1982:827). Pero, además, los So'ort se paseaban frente a la choza ceremonial, sin ingresar al campamento. Mientras que en el primer caso las mujeres se sentían amenazadas y no disfrutaban de su presencia, en el segundo caso consideraban que So'ort era hermoso (Chapman 1982:103), e incluso podían hacerlo aparecer mediante cánticos específicos (Chapman 1982:97). De esta manera, la pintura corporal de So'ort contribuía a su doble rol como agente de control social, pero también de seducción de los hombres sobre las mujeres. Esta ambivalencia de las mujeres acerca de los So'ort, facilitada por las pinturas que simultáneamente transformaban su identidad humana y los hacían bellos, permitía la continuación de las acciones de los hombres, que generaba tanto coerción física y visual sobre las mujeres como su consenso.

La manipulación de las pinturas corporales durante el hain contribuía a que los hombres generaran poder sobre las mujeres. Esto no solamente ocurría en la práctica, sino que se ve reflejado claramente en el mito de origen del hain, éste señalaba que en tiempos anteriores las mujeres habían celebrado un hain femenino, en el cual representaban ser espíritus para oprimir a los varones. Las mujeres fueron descubiertas ensayando los movimientos de los espíritus y lavándose la pintura; luego de una venganza violenta por parte de los varones, éstos generaron una versión masculina de la ceremonia con el objeto de controlar a las mujeres (Gusinde 1982:839; citamos aquí elementos relevantes a nuestra discusión; ver el análisis de este complejo mito, en Chapman 1982). Esta presentación inversa de la realidad Selk'nam en el mito, constituye claramente una justificación ideológica de la dominación masculina sobre las mujeres. A su vez, el mito arroja luz sobre la importancia dada por los hombres al uso de las pinturas como instrumento de poder durante la ceremonia y a su consecuente mantenimiento en secreto.

En contraposición a la situación de dominación masculina producida en esta ceremonia, durante el hain las mujeres realizaban parodias de algunas de sus escenas, ridiculizando la actitud de algunos espíritus (Chapman 1982:146). La parodia de algunos espíritus y escenas -no de aquellos que requerían mayor respeto- se realizaba mediante la imitación de sus movimientos, aunque aparentemente no de sus pinturas corporales.

Las mujeres también se pintaban durante el hain, en momentos especiales, cumpliendo roles particulares (como madre de un kloketen), y para determinadas danzas (p. ej., el kewanix, ver Chapman 1982:136; Gusinde 1982:958-959) ${ }^{9}$. La información indica que eran ellas las encargadas de recoger y almacenar los pigmentos (Gusinde 1982:331, 890; ver análisis de las dinámicas implicadas en el manejo de pigmentos en Fiore 2002:228). Por lo tanto, las mujeres estaban profundamente familiarizadas con la preparación y el uso de las pinturas, con lo cual el "secreto" no implicaba que ellas ignoraran por completo lo que ocurría en la choza ceremonial, tal como lo ha demostrado Chapman (1982:88, 146-147). Sin em- 
bargo, para que la presentación de los espíritus tuviera el efecto esperado, era necesario ocultar su proceso de producción.

\section{Las Pinturas Yamana. Usos e Implicaciones Sociales}

Los Yamana se pintaban el cuerpo en situaciones cotidianas y en distintas ocasiones especiales. Las primeras incluyen: el embellecimiento, las visitas, la expresión de estados de ánimo, la "venganza de sangre" (represalia de un grupo contra otro previamente agresor), la protección de la piel, la pintura para asegurar buen tiempo antes de la navegación de canales, la recuperación de una persona enferma, la pintura durante el canto de canciones (sin otro propósito conocido), el entretenimiento y la celebración de la aparición de los primeros huevos de aves en primavera (Figura 5). A excepción de la "venganza de sangre" y, en parte, de las visitas (Fiore 2002:730), el resto de estas situaciones está muy escasamente documentado, y su registro, en general, se reduce a bravísimas menciones con exiguos detalles, registrados por Bridges (1897), FitzRoy (1839), Gusinde (1986), Hya- des y Deniker (1891), Lothrop (1928), Martial (1888), entre otros.

Las ocasiones especiales incluyen: la primera menstruación, el casamiento, la celebración del amamantamiento ${ }^{10}$, la pintura de los chamanes (yekamushes), el duelo (talawaia-ceremonia individual- y yamalashemoina -ceremonia colectiva-), el chiéjaus (ceremonia de iniciación mixta) y el kina (ceremonia de iniciación masculina) (Bridges 1897; FitzRoy 1839; Gusinde 1986; Hyades y Deniker 1891; Koppers 1991; Martial 1888; Stambuk 1986; entre otros). El uso de pinturas corporales en varias de estas situaciones está mejor documentado que las situaciones cotidianas. Esto resulta interesante, ya que contradice la expectativa de hallar mayor cantidad y calidad de registros de pinturas cotidianas, si es que éstas efectivamente se usaban con frecuencia. El hecho de hallar mejores registros de ceremonias, cuando éstas eran situaciones no cotidianas, sugiere: (a) que los observadores pueden haberle dado menor importancia -y consecuentemente menor registro-a las pinturas cotidianas que a las ceremoniales, posiblemente debido al impacto visual e importancia social que las segundas tenían en comparación con las primeras, y (b) que las pinturas de

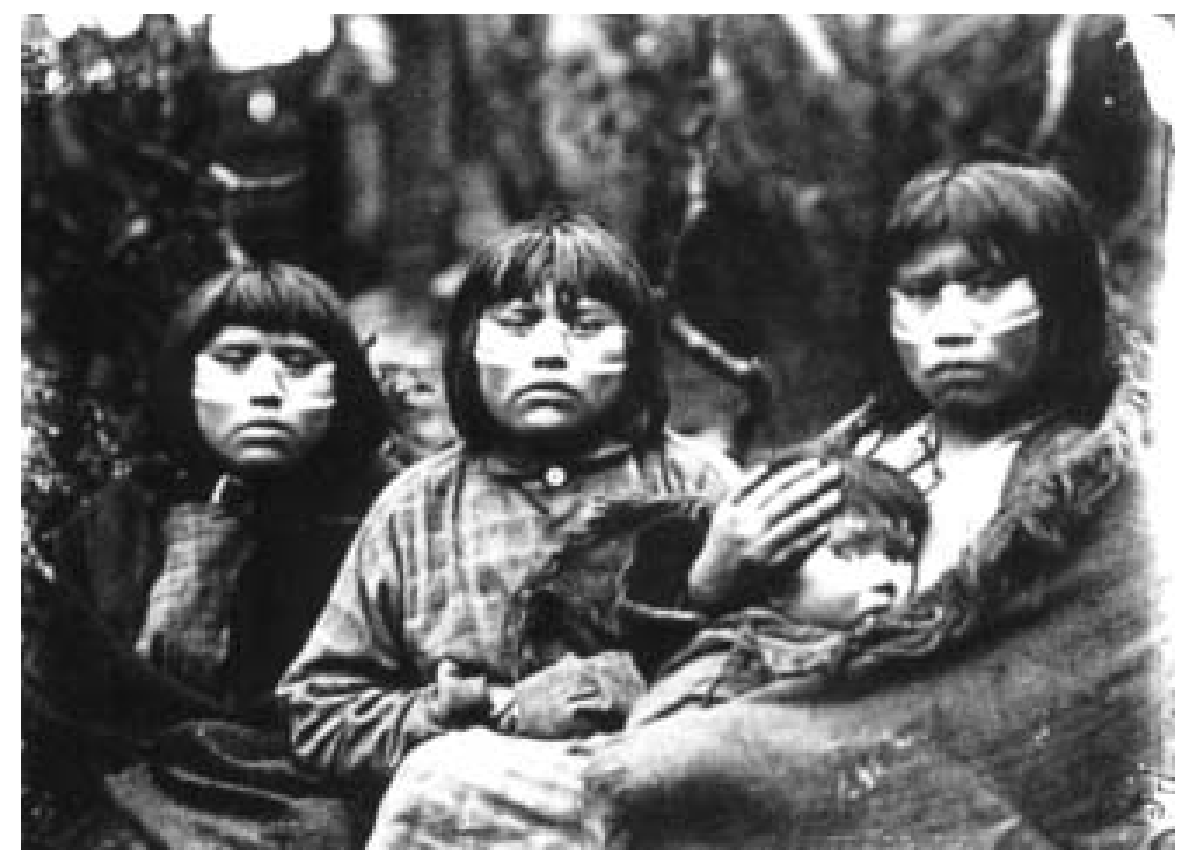

Figura 5. Mujeres Yamana usando pinturas faciales aparentemente cotidianas (foto tomada por Mission Scientifique du Cap Horn en 1882-1883, publicada por Chapman et al. 1995:110).

Yamana women wearing facial paintings apparently in an everyday situation (photo taken by Mission Scientifique du Cap Horn in 1882-1883, published by Chapman et al. 1995:110). 
situaciones cotidianas acaso no fueran empleadas tan frecuentemente, por lo menos durante la etapa de mayor contacto con poblaciones de origen europeo (siglos XIX y XX).

El chiéjaus era una ceremonia de iniciación mixta de jóvenes de ambos sexos a la adultez. Esta ceremonia fue observada en 1920 en Remolino, costa norte del canal Beagle (Gusinde 1986) y en 1922 en Mejillones, isla Navarino (Gusinde 1986; Koppers 1991). Chapman (1982) y Stambuk (1986) entrevistaron a participantes del chiéjaus $^{11}$.

La ceremonia se celebraba en una gran choza especial. Cada iniciando (uswaala) tenía dos o tres "padrinos" adultos ya iniciados, de ambos sexos (Gusinde 1986; Lothrop 1928:168). Los uswaa$l a$, padrinos y demás participantes en la ceremonia usaban pinturas corporales (Figura 6). La recolección de pigmentos para esta ceremonia era una actividad compartida (Gusinde 1986:884) y no estaba restringida a un determinado grupo etario o de sexo.

El análisis visual de los diseños empleados durante el chiéjaus muestra una preferencia por los motivos oscuros (rojos y/o negros -no distinguibles claramente en las fotografías), pintados sobre fondos blancos ${ }^{12}$. Esto contrasta con otras situaciones, tales como el kina y las pinturas de duelo, en las cuales prevalecía el uso de motivos de color blanco (Fiore 2002:315-317). No se han encontrado registros que indiquen que las pinturas del chiéjaus tuvieran algún significado, por lo cual es posible que este patrón respondiera a una razón exclusivamente estética. Sin embargo, es importante considerar: (a) que las fotografías de 1920 y 1922 de personas pintadas para el chiéjaus pueden haber sido tomadas en pocos días de cada ceremonia, y (b) que algunas de estas pinturas podrían haber sido preparadas especialmente para la sesión

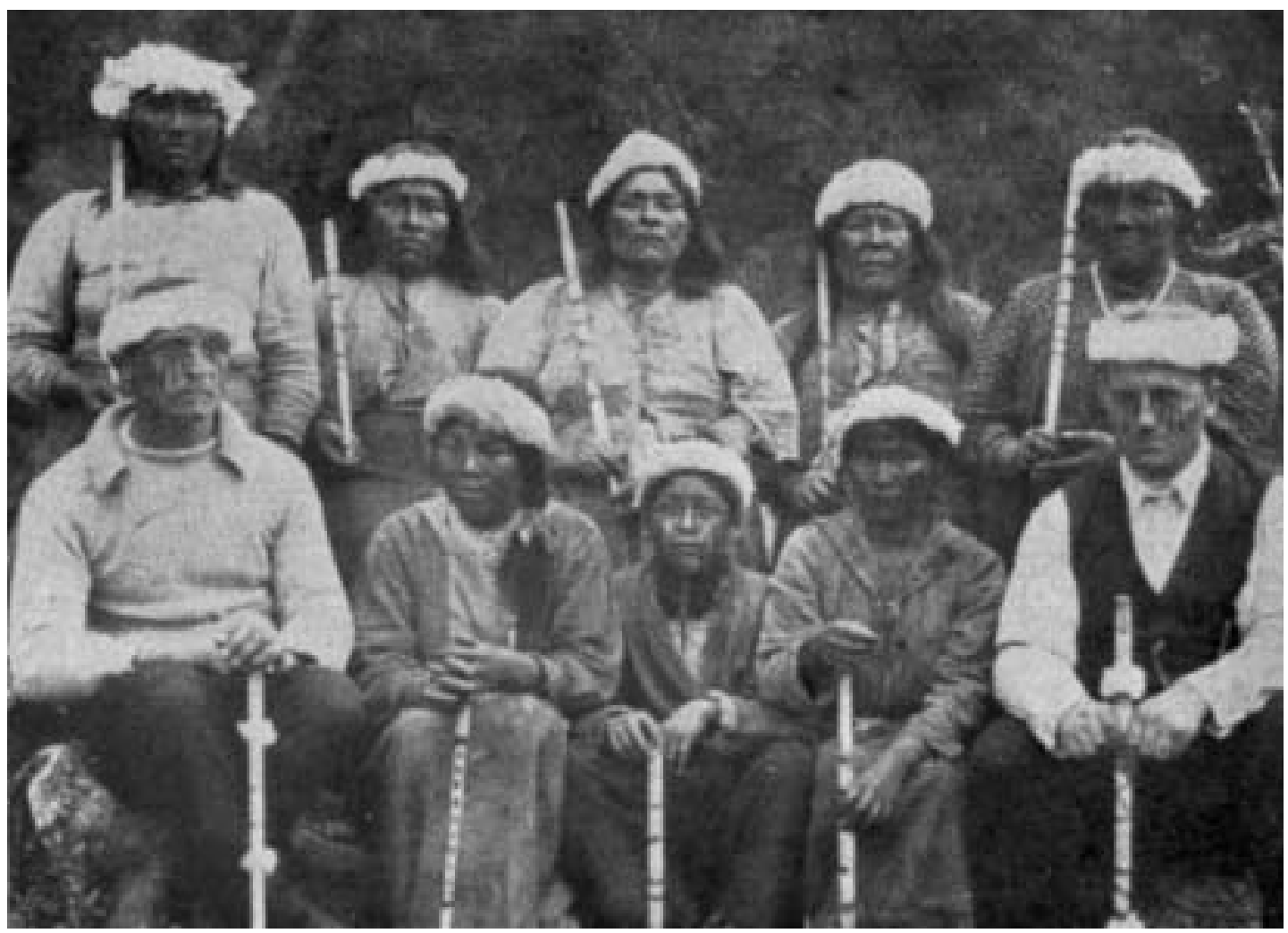

Figura 6. Grupo de personas Yamana pintado para celebrar el chiéjaus, ornamentado con diademas de plumas y sosteniendo palillos rituales decorados; nótese las dos personas de origen europeo a la izquierda y a la derecha en la primera fila: son Gusinde y Koppers, respectivamente (foto tomada por Koppers en 1922 y publicada por Koppers en 1997 [1924]:171).

Group of Yamana persons painted to celebrate the chiejjaus, ornamented with down headbands and holding ritual decorated wands; the two persons of European origin sitting in the first row in the left and right are Gusinde and Koppers, respectively (photo taken by Koppers in 1922 and published by Koppers in 1997 [1924]:171). 
fotográfica, no resultando ser una muestra enteramente representativa. Esto no elimina el patrón hallado, pero arroja luz sobre posibles sesgos en su conformación. Por otra parte, las pinturas de los uswaala eran realizadas por los "padrinos" (Gusinde $1986: 412,827,983)^{13}$, lo cual podría generar una cierta estandarización en el uso de los colores.

Aunque no hay información acerca de su potencial significado, varios de los motivos marcaban visualmente los roles de los "iniciandos" y de los adultos ya iniciados. Tal es el caso de un motivo constituido por una línea roja transversal, pintada en las mejillas, desde las aletas nasales hasta los lóbulos de las orejas, descrito por Gusinde como un diseño facial usado por los adultos en esta ceremonia (Gusinde 1986:882-884). Nueve individuos (ocho adultos y un anciano) han sido identificados utilizando este motivo en fotografías del chiéjaus, mientras que ningún joven aparece usándolo; esto confirma la descripción de Gusinde y sugiere la exclusividad del uso de este motivo por personas ya iniciadas. Gusinde describió otros motivos que eran utilizados por los uswaala, pero no exclusivamente, ya que los adultos también podían usarlos (Gusinde 1986:827-837). Esta descripción es consistente con el hecho de que del total de individuos observados en fotografías del chiéjaus, los jóvenes solamente llevaban cuatro tipos de motivos, mientras que los adultos usaban 15 , incluyendo dos de los más frecuentemente usados por los jóvenes (Fiore 2002:309). De esta manera, el panorama indica que: (a) los jóvenes usaban motivos menos variados y menos específicos, y (b) los adultos tenían el derecho / la expectativa de usar motivos más variados, algunos de los cuales eran exclusivos de su rol. Más aún, mientras que los jóvenes solamente aparecen en las fotografías con sus caras y brazos pintados, los adultos se pintaban caras, brazos, troncos y piernas, marcando otra diferenciación visual en sus roles (Fiore 2002:305).

El kina era la otra gran ceremonia de iniciación celebrada por los Yamana. Menciones relativas a ella se encuentran en Bridges (1897), pero sólo en 1922 fue observada por Gusinde (1986) y Koppers (1991). Se trata de una ceremonia de iniciación masculina a la adultez que los candidatos podían atravesar luego de haber pasado el chiéjaus dos veces (Gusinde 1986:1358). El kina se celebraba en una choza especial e incluía la representación de una gran cantidad de espíritus por hom- bres pintados y enmascarados (Figura 7). De esta manera, los iniciandos tenían acceso al "secreto" del uso de máscaras y pinturas para mantener a las mujeres sumisas y controladas.

Existe una gran discrepancia entre la información visual y la escrita acerca de los "espíritus" del kina. Las fotografías no documentan la variedad de diseños que se mencionan en los textos. La razón por la cual Gusinde y Koppers no fotografiaron mayor cantidad de "espíritus" no está clara. Es posible que no fotografiaran la totalidad de los espíritus presentados y que solamente los registraran por escrito. Además, durante la ceremonia observada en 1922 algunos espíritus no fueron repre-

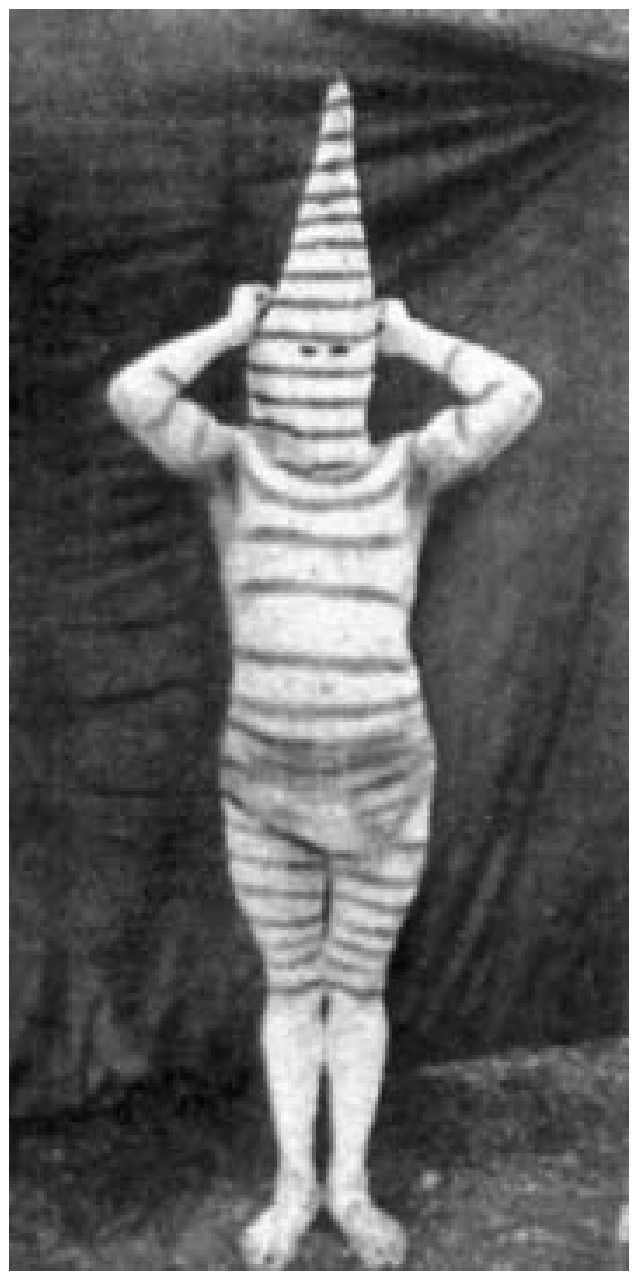

Figura 7. Espíritu Yamana del kina, de nombre desconocido (foto tomada por Gusinde en 1922 y publicada en 1937: apéndice, figura 30).

Yamana kina spirit -of unknown name (photo taken by Gusinde in 1922 and published in 1937: appendix, figure 30). 
sentados, con lo cual el resto fue citado por Gusinde a partir del diccionario de Bridges (1933, que los nombra, pero no los describe). Es también posible que, aunque no hubieran sido representados, algunos espíritus hayan sido descritos oralmente por informantes, y que consecuentemente no aparezcan fotografiados.

Se han identificado 47 espíritus descritos en los textos; éstos eran "visibles" y, por lo tanto, se presentaban frente a los no iniciados (mujeres y niños) con pinturas y máscaras (o cueros, ramas o pintura cubriendo sus cabezas). La búsqueda de posibles patrones en los diseños de estos espíritus se realizó relacionándolos con sus referentes (en su mayoría animales) y con sus lugares de proveniencia (el cielo, el bosque y el mar). Mientras que el análisis de estos últimos no fue fructífero, debido a limitaciones en la información (lo cual no permite evaluar si efectivamente existió o no un patrón visual al respecto), la relación entre referentes y diseños permitió señalar la existencia de algunas tendencias. De esta manera, fue posible establecer que todos los diseños eran representativos, y que por lo menos algunos de éstos representaban de manera icónica al referente en cuestión, ya que determinadas porciones de los diseños figuraban determinadas porciones de los referentes. Por ejemplo, los espíritus Kalampasa, Wongoaleaka y Sunayaka, eran peces, y los semicírculos pintados en el cuerpo representaban las escamas. Otros potenciales patrones no parecen haber sido icónicos. Tal es el caso de los dos únicos espíritus del mar que no eran ni peces ni mamíferos marinos -un pulpo y un calamar-, que eran pintados exclusivamente con una base roja y se distinguían por sus máscaras (Fiore 2002:332-335). Otros casos eran también icónicos, pero más ambiguos: los espíritus de un delfín y un pingüino eran pintados con una base negra y una banda blanca (ubicada en una posición específica en cada uno), lo cual haría referencia a sus apariencias reales; sin embargo, varios diseños de aves también se estructuraban de esta manera, y aunque el pingüino pueda haber sido considerado como tal, no está clara la razón por la cual el delfín sería pintado de modo similar (Fiore 2002). Esto sugiere que el código visual habría definido los diseños de cada espíritu individual, pero no siempre de acuerdo a categorías mayores ("peces", "aves") que los agruparan, o que fueran coincidentes con las muestras disponibles. A esto se suma el hecho de que los espíritus eran anuncia- dos verbalmente (Gusinde 1986:1337), lo cual indica que su apariencia no era suficiente como para comunicar visualmente su identidad. Es posible que esto se haya debido tanto a cierta laxitud del código visual del kina como a la circunstancia de que en 1922 esta ceremonia no había sido celebrada desde hacía aproximadamente 30 años (desde 1892: Gusinde 1986); lo que habría debilitado considerablemente la tradición visual y mitológica que permitía la construcción y decodificación de los diseños.

Aunque era una ceremonia principalmente masculina, pocas mujeres eran invitadas a participar del kina y conocían así el "secreto". Siendo ya iniciadas, podían participar del "engaño", por ejemplo, al aparentar que huían del ataque de espíritus malignos e "invisibles", salían de la choza ceremonial con sus narices sangrantes para simular haber sido atacadas (Gusinde 1986:1302). Pese a que la inclusión de las mujeres estaba controlada por los hombres, esto generaba una división interna dentro del género femenino, dándole cierta situación de poder a las mujeres iniciadas, tenían acceso a espacios ceremoniales, información y prácticas (incluyendo el uso de técnicas de pintura), restringidos al resto de la población femenina (Fiore 2003).

Esta mayor amplitud de los Yamana con respecto a la inclusión de algunas mujeres en el kina se registra también en el hecho de que permitieron a Gusinde fotografiarlos mientras decoraban una máscara (en la misma fotografía se observa en segundo plano a otro individuo colocándose una máscara), lo cual indica su falta de reserva con respecto al mantenimiento del "secreto". Sin embargo, es posible también que este menor hermetismo se debiera -por lo menos en parte- a un deterioro de las tradiciones ceremoniales Yamana a causa de la profunda aculturación que éstos habían sufrido en el momento que esta ceremonia fue observada por Gusinde. Un indicador de este proceso de transformación cultural es que en todas las fotografías de dicha ceremonia (y en las fotografías contemporáneas) todos los individuos de esta sociedad aparecen vestidos con ropas occidentales. Esto contrasta claramente con su vestimenta típica, documentada en textos desde el siglo XVII y en fotografías del siglo XIX, que dejaba desnudas amplias porciones del cuerpo.

El menor hermetismo de los Yamana en cuanto al kina coincide con los contenidos de algunos de sus mitos. El mito de origen sostenía que ante- 
riormente las mujeres habían celebrado esta ceremonia y personificado espíritus para someter a los hombres, y que éstos, al descubrir el engaño, iniciaron la ceremonia con el objeto de controlarlas. Pero una historia contada por las mujeres Yamana afirmaba que en el pasado una mujer pintada como los hombres había logrado introducirse en la choza ceremonial y pintar en la espalda de cada hombre una línea sin que ellos lo percibieran. La mujer avisó a las demás mujeres, y cuando los hombres salieron de la choza -cada uno con la línea pintada en la espalda- se reveló su identidad humana ( $\mathrm{Gu}-$ sinde 1986:1356-1357). Mientras que el mito presenta una justificación ideológica de la práctica básicamente masculina del kina, la historia citada refleja no solamente el conocimiento femenino del "secreto", sino que constituye una enunciación del poder potencial del uso de la pintura para equiparar una situación desigual en favor de las mujeres Yamana.

\section{Conclusiones. El Mundo Visual y el Mundo Social en Tierra del Fuego}

El panorama sintético aquí expuesto permite marcar una serie de semejanzas y diferencias en el uso de pinturas corporales por los Selk'nam y los Yamana. En ambas sociedades se observa una tendencia en las mujeres a usar más frecuentemente pinturas faciales, mientras que los hombres usaban pinturas faciales y corporales en frecuencias más parejas. Esto marca en ambos casos una diferencia de sexo relativa a qué porciones del cuerpo podían pintarse, exhibirse y ser fotografiadas. Aunque estas diferencias de sexo posiblemente respondieran a influencias de los procesos de aculturación, éstos no parecen haber tenido el mismo impacto en ambas sociedades, a juzgar por las diferencias halladas en las porciones del cuerpo que los hombres Selk'nam y Yamana se pintaban; esto implica que sus respectivos patrones culturales habrían influido también en las trayectorias de cambio frente al contacto con poblaciones occidentales.

Las diferencias intersociales también se registran, en el caso Selk' nam se observan en las fotografías muchos más hombres pintados, mientras que en el caso Yamana la cantidad de hombres y mujeres pintados es homogenea. Aunque pueda deberse a sesgos en los registros (comentados anteriormente), esto coincide con el hecho de que en la sociedad Selk'nam el dominio masculino era ma- yor que en la Yamana. Otra diferencia entre ambas sociedades radica en el repertorio de motivos: aunque varias técnicas y elementos básicos eran compartidos, los motivos eran primordialmente distintos (Fiore 2002:716) ${ }^{14}$.

Como hemos visto, las pinturas eran utilizadas en muchas situaciones similares, tanto cotidianas como especiales. Sin embargo, resulta claro que la dinámica de uso de las pinturas corporales ceremoniales era considerablemente distinta en ambas sociedades. Esto se evidencia, por ejemplo, en los roles asumidos por varones y mujeres Selk'nam y Yamana, marcados por su acceso al empleo de pinturas. Aunque en estas sociedades existían diferencias de sexo, en los Yamana hombres y mujeres participaban de las pinturas ceremoniales centrales a la iniciación de los jóvenes en el chiéjaus, e incluso en el kina no existía una total exclusión de las mujeres de dichas prácticas. En el caso Selk'nam las mujeres también manejaban pinturas, pero se veían excluidas de los roles de mayor poder, desempeñados por hombres, a los que prestaban consenso, por: (a) la coacción física y verbal ejercida por los hombres; (b) empatía hacia ellos (por presentarse como víctimas de los espíritus), y (c) la seducción que ellos generaban mediante su presentación pintados con diseños estéticamente bellos y simbólicamente apreciables por las mujeres (p. ej., diseños de espíritus relativos a sus linajes de origen $)^{15}$. Estas disímiles dinámicas en el manejo de las pinturas ceremoniales se correlacionan con las reacciones de ambos grupos hacia la fotografía del proceso de pintura corporal de los espíritus: los Selk'nam evitaron ser fotografiados e incluso atacaron a Gusinde cuando éste intentó hacerlo, en tanto los Yamana no parecen haber tenido ningún reparo al respecto. Aunque estas reacciones, podrían ser parcialmente efecto de distintos procesos de aculturación y de degradación de las respectivas tradiciones ceremoniales, también indican la importancia diferente que tenía para cada grupo el mantenimiento del "secreto", lo que coincide con la absoluta exclusividad masculina del hain y la invitación selectiva de algunas mujeres al kina.

En ambas sociedades, las situaciones de diferencias internas de género coinciden con los contenidos de los mitos de origen del hain y del kina. En éstos existe una justificación ideológica que invierte la situación real y representa como necesaria la dominación de las mujeres por los hom- 
bres. También en ambas sociedades las mujeres crearon formas de expresión -tanto historias orales (caso Yamana) como prácticas que se mofaban de la ceremonia (caso Selk'nam)-mediante las que invertían simbólicamente la situación de dominación masculina, aliviando la tensión creada durante estas ceremonias.

Las dinámicas identificadas en las esferas de producción artística y mítica son, a su vez, vinculables con los roles asumidos por hombres y mujeres en las esferas de subsistencia y movilidad en cada sociedad. El caso Selk'nam, donde la división de género aparece más marcada, coincide con una división sexual del trabajo en la que los hombres se dedicaban a la caza y eran los principales proveedores del sustento, en tanto las mujeres estaban a cargo de la movilidad de la unidad doméstica, transportando los armazones de las chozas plegadas cuando se trasladaban de un sitio a otro, también documentado fotográficamente (De Agostini 1924; Gusinde 1982). En el caso Yamana también existía división del trabajo por género, pero incluía la cooperación en una tarea fundamental para la subsistencia: las mujeres remaban las canoas desde las cuales los hombres capturaban pinnípedos y otros animales marinos; con lo cual estaban a cargo de la movilidad, pero también cumplían un papel más activo de obtención de la subsistencia (Gusinde 1986; Martial 1888).

En consecuencia, considerando las expectativas planteadas al inicio de este trabajo, las diferencias intersociales de estructuración de las prácticas de pintura corporal se vinculan tanto a factores internos como externos a esta esfera de producción en cada sociedad. Las diferencias no estaban dadas fundamentalmente por el acceso a materias primas, técnicas e instrumentos, que eran similares en ambas sociedades, sino por el acceso diferencial al conocimiento y control sobre los diversos manejos de las pinturas de acuerdo al género y la edad de las personas. Pero, además, las divisiones sociales internas a estas prácticas coinciden en cada grupo con otras divisiones externas a éstas. Las formas de organización de estas actividades marcan contextos sociales diferentes entre sí, donde cada uno es coherente con las dinámicas de uso de pinturas identificadas en cada sociedad. Esto sugiere que en cada sociedad todas esas actividades tenían patrones de organización con cierto grado de coherencia entre sí. Estos patrones incluían fuertes desigualdades de sexo en la sociedad Selk'nam y diferencias de sexo -pero con mayor complementariedad- en la sociedad Yamana. A esto se sumaba la justificación ideológica de estas diferencias y desigualdades mediante los mitos, que facilitaban la reproducción del sistema social en el tiempo, de una generación a la siguiente, ya que mitigaba las posibles contradicciones internas a cada sistema, haciendo aparecer como necesarias y naturales a las prácticas ceremoniales que de hecho favorecían la producción de divisiones sociales. Con sus peculiares dinámicas, el arte visual Selk'nam y Yamana contribuía, sin dudas, a crear el mundo social de cada uno de estos grupos en el confín del mundo.

Agradecimientos: Este trabajo sintetiza algunos de los resultados obtenidos en mi tesis doctoral; quiero agradecer a Stephen Shennan, mi director, por su constante estímulo, sus agudas preguntas y la precisión de sus comentarios. A mis codirectores Jeremy Tanner por su gran entusiasmo y detallados comentarios y Bill Sillar por sus inquietudes y originales sugerencias. A Luis A. Orquera por su constante apoyo, por su generosidad al responder cada una de mis preguntas sobre la historia, etnografía y arqueología de Tierra del Fuego, y por ofrecerme acceso a la Asociación de Investigaciones Antropológicas, donde consulté gran parte de las referencias necesarias para esta investigación. A Ernesto Piana, Estela Mansur y Luis Borrero, por brindarme acceso a su colección de registros visuales de Tierra del Fuego y por sus comentarios en distintos momentos de la investigación. A la Royal Geographical Society (Londres), al Archivo Salesiano (Buenos Aires) y la Biblioteca del Museo Etnográfico "J.B. Ambrosetti" (UBA), por permitirme el acceso a sus archivos y colecciones. Finalmente, quiero agradecer a Calogero Santoro por haberme invitado a escribir este trabajo. Los contenidos de éste son, por supuesto, de mi exclusiva responsabilidad. La tesis doctoral fue generosamente apoyada mediante becas de University College London, el Council of Vice-Chancellors and Principals of the United Kingdom, y Fundación Antorchas (Argentina). A todas estas instituciones les estaré siempre muy agradecida. 


\section{Referencias Citadas}

Barclay, W.

1926 The Land of Magellan. Methuen \& Co, Londres.

Beauvoir, H.M.

1915 Los Selk'nam: Indígenas de la Tierra del Fuego. Sus Tradiciones, Costumbres y Lengua. Tipografía Salesiana de Artes y Oficios, Buenos Aires.

Belza, J.

1974 [1914] Acta Indiorum. Texto original de misionero salesiano anónimo. Karukinka 9:iii-xii.

Bridges, $\mathrm{T}$.

1897 An Account of Tierra del Fuego (Fireland), its Natives and their Languages. Documento en la Royal Geographical Society. Copia en poder de R.N.P de Goodall. Manuscrito.

Bridges, L.

1935 Supersticiones de los Onas. Argentina Austral 73:33-39.

1951 Uttermost Part of the Earth. Hodder and Stronghton, Londres.

Chapman, A.

1982 Drama and Power in a Hunting Society: the Selk'nam of Tierra del Fuego. Cambridge University Press, Cambridge.

Collier, J. Jr.

1975 Photography and visual anthropology. En Principles of Visual Anthropology, editado por P. Hockins, pp. 211230. Mouton, Paris.

De Agostini, A.

1924 I miei viaggi nella Terra del Fuoco. Società Salesiana, Milán.

1945 Andes Patagónicos. Viajes de Exploración a la Cordillera Patagónica Austral. Peuser, Buenos Aires.

Fiore, D.

2002 Body Painting in Tierra del Fuego. The Power of Images in the Uttermost Part of the World. Doctoral Thesis, University of London, UCL, Institute of Archaeology, Londres.

2003 Painted genders: the construction of gender through the display of body painting by the Selk'nam and the Yámana from Tierra del Fuego (southern South America). Women in Archaeology. Women in Antiquity, editado por S. Hamilton, R. Whitehouse y K. Wright. University College London Press, Londres, en prensa.

2004a Pieles rojas en el confín del mundo. La valoración de las pinturas corporales en los registros histórico-etnográficos sobre aborígenes de Tierra del Fuego. Magallania 32:29-52.

2004b The shadow hunter and the eye of the camera. Issues on the construction of ethnographic photography in Tierra del Fuego. Manuscrito en posesión de la autora.

Fitz-Roy, R.

1839 Proceedings of the second expedition (1831-1836) under the command of captain Robert Fitz-Roy (R.N.). Narrative of the Surveying Voyages of His Majesty's Ships Adventure and Beagle Between the Years 1826-1836... Vol. II. Henry Colburn, Londres.

Gallardo, C.

1910 Los Onas. Cabaut y Cía., Buenos Aires.
Gusinde, M.

1951 Fueguinos. Hombres Primitivos en la Tierra del Fuego (de investigador a compañero de tribu). Escuela de Estudios Hispanoamericanos (serie $3, N^{0} 5$ ), Sevilla.

1982 [1931] Los Indios de Tierra del Fuego. I. (1 y 2). Los Selk'nam. Traducido bajo la dirección de W. Hoffmann. Centro Argentino de Etnología Americana, Buenos Aires. 1986 [1937] Los Indios de Tierra del Fuego II (1, 2 y 3). Los Yamana. Traducido bajo la dirección de W. Hoffmann. Centro Argentino de Etnología Americana, Buenos Aires. 1989 [1939] Los Indios de Tierra del Fuego. IV (1 y 2). Antropología Física. Traducido por H. Jung y C. Hedwig Romero. Centro Argentino de Etnología Americana, Buenos Aires.

Hyades, P. y J. Deniker

1891 Antropología y etnografía. En Mission Scientifique du Cap Horn (1882-1883). Vol 7. Paris.

Koppers, W.

1997 [1924] Entre los Fueguinos. Traducido por C. Brinkmann. Universidad de Magallanes y Programa Chile Austral de la Unión Europea, Punta Arenas.

Lista, R.

1887 Viaje al País de los Onas. Alberto Núñez, Buenos Aires. Lothrop, S.K.

1928 The Indians of Tierra del Fuego. Museum of American Indian. Contributions 10, Heye Foundation, New York.

Martial, L.F.

1888 Histoire du voyage. En Mission Scientifique du Cap Horn (1882-1883). Vol 1. Paris.

Massone, $\mathrm{M}$.

1989 Los cazadores de Tierra del Fuego $(8000 \mathrm{aC}$ al presente). En Culturas de Chile. Prehistoria. Desde sus Orígenes Hasta los Albores de la Conquista, editado por J. Hidalgo, V. Schiappacasse, H. Niemeyer, C. Aldunate e I. Solimano, pp. 349-366. Andrés Bello, Santiago de Chile.

Orquera, L.A. y E.L. Piana

1999 Arqueología de la Región del Canal Beagle (Tierra del Fuego, República Argentina). Publicaciones de la Sociedad Argentina de Antropología, Buenos Aires.

Ortiz Troncoso, O.

1989 Ancestros de los pescadores australes $(8000 \mathrm{aC}$ a ca. $1500 \mathrm{dC}$ ). En Culturas de Chile. Prehistoria. Desde sus Orígenes Hasta los Albores de la Conquista, editado por J. Hidalgo, V. Schiappacasse, H. Niemeyer, C. Aldunate e I. Solimano, pp. 367-379. Andrés Bello, Santiago de Chile.

Prieto, A. y R. Cárdenas

1997 Introducción Étnica a la Fotografía en Patagonia. Editorial Comunicaciones, Punta Arenas.

Scherer, J.

1992 The photographic document: photographs as primary data in anthropological enquiry. En Anthropology and Photography. 1860-1920, editado por E. Edwards, pp. 32-41. Yale University Press, New Haven-Londres.

Segers, P.

1891 Tierra del Fuego. Hábitos y costumbres de los indios Aonas. Boletín del Instituto Geográfico Argentino XII:56-82. Stambuk, P.

1986 Rosa Yagán. El Ultimo Eslabón. Andrés Bello, Santiago. 


\section{Notas}

1 Este número se reduce al excluir las repeticiones de individuos que aparecen en dos o más fotografías tomadas en exactamente el mismo lugar y con el mismo diseño pintado, las que corresponden a tomas sucesivas de un mismo hecho. Estas repeticiones se eliminaron al realizar análisis cuantitativos, ya que de otra manera se sesgaría la muestra, aumentando ficticiamente el número de ciertos casos en detrimento de otros, alterando así las frecuencias y proporciones de uso de un diseño.

2 Existen algunas menciones del uso de naranja/amarillo para el caso Selk'nam.

3 Desconocemos si en Tierra del Fuego existen otras materias primas que puedan utilizarse para crear otros colores. En caso afirmativo, esto implicaría la existencia de limitaciones tecnológicas para procesar los materiales o estéticas en la elección (y descarte) de otros colores.

4 La identificación del género de los niños y bebés es en algunos casos dudosa.

5 Calculado excluyendo a las categorías de bebés y ancianos debido a sus bajas frecuencias.

6 Este libro menciona también el dato de que otros hain se habían celebrado en 1920 y 1933 (Chapman 1982).

7 Esto no significa que tanto hombres como mujeres no creyeran en los espíritus, ya que efectivamente creían en su existencia (Chapman 1982:97)

8 Existen discrepancias entre Gusinde (1982) y Chapman (1982) acerca del género de algunos espíritus.

9 En este caso, un complejo código visual permitía representar el linaje al que pertenecía cada individuo, refiriéndose simultáneamente a tres niveles de referentes -ancestros míticos, harwins (territorios) y so'ons (cielos)- de manera aparentemente abstracta, no-icónica (Chapman 1982:136; Fiore 2002:399-408; Gusinde 1982:961).

10 Se trata de una única observación realizada por Hyades y Deniker, quienes registraron el uso de pinturas por mujeres cuando otra mujer iniciaba el amamantamiento de su bebé recién nacido (Hyades y Deniker 1891:194).

11 Lakutaia Le Kipa, entrevistada por Stambuk, menciona que otro chiéjaus se había celebrado en 1910 (Stambuk 1986).

12 El chiéjaus incluía la aparición de un espíritu (Yetaita), representado por un hombre con pinturas faciales y corporales (Chapman 1997:84). Debido a la escasez de información acerca de sus diseños, no incluimos aquí referencia al respecto.
13 Ver en Stambuck (1986) el comentario de Lakutaia Le Kipa sobre su rol pintando participantes cuando aún era joven.

14 No obstante, es interesante observar la similitud en la estructura básica de los diseños de espíritus del hain y del kina: antebrazos y pantorrillas generalmente blancos, resto del cuerpo con un color de base y motivos sobre esta base con colores contrastantes, y uso de máscaras pintadas. Dos opciones surgen como potenciales causas de este fenómeno: un origen común de ambas ceremonias, o la transmisión de esta práctica de una sociedad a otra. Los textos históricos y etnográficos no proporcionan evidencias respecto de la primera opción. A esto se suman las profundas diferencias en los modos de vida de ambas sociedades (en formas de subsistencia, tecnología, división del trabajo, roles sociales, mitos, lengua, etc.), lo cual sugiere que si estas pinturas (y ceremonias) hubieran tenido un origen común: (a) éste se apartaría de las diferencias observadas en las otras esferas sociales arriba citadas, y (b) éste se remontaría a tiempos tempranos (divergiendo posteriormente y manteniendo semejanzas básicas), momentos para los cuales no poseemos datos que corroboren o refuten esta posibilidad.

En relación a la segunda opción, tanto Gusinde (1986:1358) como Chapman (1987:86) consideran que el origen del kina se debe a una influencia Selk'nam. Esta interpretación se basa en el hecho de que la estructura social Yamana no estaba basada en una dominación masculina tan marcada como la Selk'nam, con lo cual la dinámica de control femenino mediante esta ceremonia no resultaría del todo coherente con la sociedad Yamana. Por otra parte, Koppers (1991:156) menciona información sobre posibles influencias Alacaluf -cuya estructura social no estaba basada profundamente en la dominación masculina-sobre el origen del kina. En estos casos, la transmisión habría implicado necesariamente un íntimo contacto entre grupos de ambas sociedades, de manera que pudieran tener acceso a algunas de las prácticas sociales más reservadas de la sociedad potencialmente "transmisora" de esta ceremonia. La información histórica y etnográfica no parece indicar que existieran contactos de tal magnitud, pero esto puede deberse a sesgos en los registros, con lo cual la posibilidad no puede ser descartada.

15 A esto se sumaba la integración entre géneros mediante juegos y danzas (como el kewanix). 
